\title{
Tratamiento de la verdad entre Lacan y Derrida
}

\section{On truth in Lacan and Derrida}

\section{María Laura Frucella}

\section{RESUMEN:}

El presente escrito esboza un planteo del tema de la verdad en Jacques Lacan y Jacques Derrida, al tiempo que pone en primer plano los puntos controversiales entre ambos autores. No constituye un rastreo exhaustivo de la concepción de verdad en uno y otro; antes bien, realiza un relevamiento de los ejes según los cuales se aloja esta temática en cada uno y los virajes que se operan a lo largo de sus producciones. Deconstrucción y psicoanálisis están más cerca de lo que estos dos grandes representantes están dispuestos a admitir. El artículo concluye, pues, tratando de situar los puntos irreconciliables de una y otra perspectiva, así como aquello que podría constituir un punto en común en el abordaje de la problemática de la verdad.

\section{Palabras Clave:}

Jacques Lacan - Jacques Derroda verdad - ficción - mentira

\section{SUMMERY:}

This paper outlines a statement of the truth issues in Jacques Lacan and Jacques Derrida, while it puts in the forefront the controversial points between both authors. It doesn't constitute an exhaustive tracking of the conception of truth in their works; instead of that, it makes a survey of the axes according to which this theme is placed in each one and the variations operated throughout its productions. Deconstruction and psychoanalysis are closer to what these two great authors are willing to admit. The article concludes, then, trying to situate the irreconcilable points of both perspectives, as well as what could constitute a common point in the approach to the problematic of truth.

\section{WORD PAD:}

Jacques Lacan - Jacques Derrida -

Truth - Fiction - Lie 



\section{LA VERDAD EN LACAN, SEGÚN DERRIDA}

Habiéndome dedicado durante cierto tiempo a entender el punto controversial entre Lacan y Derrida en relación con la escritura, me propongo ahora simplemente introducirme en el tema de la verdad, que está en primer plano entre los argumentos con que Derrida critica la producción lacaniana.

No en vano, en el texto que le dedica íntegramente al análisis del Seminario sobre La carta robada y otros escritos de Lacan, pone desde su título a la verdad en primer plano: me refiero a Le facteur de la vérité, vertido al castellano como $\mathrm{El}$ concepto de verdad en Lacan.

Allí, Derrida comienza objetando al psicoanálisis por el modo en que, a su modo de ver, procede con los textos, esto es, quitando uno a uno los diferentes ropajes que constituyen las "elaboraciones secundarias" para acceder al contenido primario, que equivaldría a cierta verdad última. Se trataría, también, de la manera de operar del psicoanálisis en tanto práctica clínica al aplicarse al desciframiento de las formaciones del inconsciente -notemos que la expresión "envoltura formal del síntoma” (Lacan 2002, 74), que Lacan utiliza a inspiración clérambaultiana, nos pone en la perspectiva de un conglomerado que hay que desarropar para poder abordarlo en su núcleo-.

Sin embargo, el proyecto de descubrir, desenmascarar, apartar el velo para mostrar la verdad que subyace está, antes que en el psicoanálisis, en el inicio mismo del plan metafísico. La verdad como ser que reposa debajo de las apariencias del ente, como presencia que debe recuperarse, devolverse a la "luz" mediante la operación de la inteligencia constituye, según Derrida, el procedimiento de la tradición filosófica occidental por excelencia. El psicoanálisis compartiría con ella este modo de operar, basándose, en su caso, en la lisis, esto es, la descomposición de un elemento complejo en las distintas partes que lo conforman. Así, un texto sería tomado como una Einkleidung, un vestido del cual se irían levantando uno a uno los velos que recubren la aletheia, la verdad "desnuda" subyacente. Esta idea de la “verdad como desnudez" estaría presente en los análisis freudianos de obras literarias -Edipo rey, Hamlet, los dramas de Ibsen, los cuentos de Hoffman, la Gradiva de Jensen, el Fausto de Goethe, Los hermanos Karamazov de Dostoievski, o los versos de Schiller, entre tantos otros-.

Pero la impugnación derridiana no recae sobre el gesto de ir siguiendo el izamiento de capas textuales al infinito, sino sobre la esperanza, mal disimulada, de dar por fin con algo estable y final, una especie de verdad terminal. Cuando Derrida reprocha la estrategia desenmascarante a la filosofía y al psicoanálisis, de ningún modo propone detener el curso de las remisiones ininterrumpidas de signos a signos -lo cual no es tampoco ajeno al proyecto de la deconstrucción- sino que alerta sobre la posibilidad de cualquier tope que pueda emplazarse en el lugar de una verdad última. Es por ello que la noción de falo es, en el corpus lacaniano, uno de los elementos que más recibe sus críticas.

\section{LA VERDAD Y SU ESTRUCTURA DE FICCIÓN}

La cuestión de la verdad aparece en Lacan indisolublemente enlazada a la palabra ya desde sus primeras producciones. "Sólo 
con la dimensión de la palabra se cava el surco de la verdad en lo real. Antes de la palabra no hay verdadero ni falso" (Lacan 1981, 333) afirma Lacan en el Seminario 1, donde también presenta la distinción entre "palabra (o habla) vacía” y "palabra plena", siendo esta última la que "realiza la verdad del sujeto" (Lacan 1981, 84).

Las objeciones de Derrida a este modo de situar la verdad no dejan de pronunciarse desde sus primeros textos: ya en $D e$ la gramatología afirma que no hay esa tal palabra plena "que dice ser la verdad" (Derrida 1986, 90), puesto que una palabra así sólo se pronunciaría en la ilusoria plenitud de un presente y una presencia absoluta, imposibles de sostenerse si se tiene en cuenta al signo como elemento tomado en la problemática de la huella.

La distinción entre parole plein y parole vide no aparece más que en los primeros seminarios y escritos de Lacan. Incluso en el Seminario 3 Las psicosis le hace sufrir un viraje: la palabra plena no es ya la que dice la verdad del sujeto sino aquella que llena la boca del delirante produciéndole satisfacción. Y sin embargo Derrida sigue reprochándoselo aún en un texto del año 92, Pour l'amour de Lacan, junto con lo que considera el modo de entender la verdad propio del discurso lacaniano, esto es, la verdad como develamiento, al estilo heideggeriano.

Sin duda uno de los problemas de la controversia entre Lacan y Derrida es el anacronismo: puesto que Derrida no ha seguido el derrotero del pensamiento lacaniano hasta sus últimas producciones, su crítica nos deja muchas veces la sensación de estar desactualizada. En El concepto de verdad en Lacan, Derrida admite que, con posterioridad a 1966, "el discurso lacaniano sobre la verdad (...) se ha prestado
(...) a cierto número de adecuaciones de no poca monta o de retoques decisivos", pero no es notable un interés de Derrida por indagar en esos "retoques".

En Subversión del sujeto y dialéctica del deseo en el inconsciente freudiano, Lacan afirma que la verdad concierne a una realidad, pero saca su garantía no de ella sino de la palabra y su estructura de ficción. Lacan toma la idea de que la verdad tiene estructura de ficción de la Teoría de las ficciones, de Jeremy Bentham, y lo hace explícito en la primera parte de Reseñas de enseñanzas, cuando indica que en esa obra, "fictitious" no significa engañoso ni ilusorio, sino homólogo a la estructura de la ficción. En ese sentido, agrega allí Lacan, el mismo inconsciente tiene estructura de ficción por el hecho de ser un discurso, lo cual queda probado, agrega, por el placer que produce la repetición de un signo.

Pensemos en la expresión freudiana "novela familiar" -Familienroman- para referirse a la historización autobiográfica del neurótico en análisis: ella nos habla de la invención que hace el analizante de su pasado familiar, cual si de un escritor se tratara.

¿Qué significa que la verdad tiene estructura de ficción? Que lo verdadero está dado por el orden del significante y la palabra. Aun cuando pueda haber en ella un fingimiento, una fabulación, como ocurre en las obras literarias, la verdad se impone por el hecho de habitar la palabra, de residir en ella, tal como lo condensa el neologismo usado por Lacan muchos años más tarde: dit-mension, en donde se oye lo dicho -dit-, la casa -maison- y la mentira -mens-.

Lo verdadero no se opone ni a lo ficticio ni a la mentira, siendo posible men- 
tir con la verdad, tal como lo muestra el chiste freudiano. (Recordémoslo: "En una estación ferroviaria de Galitzia, dos judíos se encuentran en el vagón. "¿Adónde viajas?”, pregunta uno. “A Cracovia”, es la respuesta. “¡Pero mira qué mentiroso eres! -se encoleriza el otro-. Cuando dices que viajas a Cracovia me quieres hacer creer que viajas a Lemberg. Pero yo sé bien que realmente viajas a Cracovia. ¿Por qué mientes entonces?" (Freud 1976, 108).

El sujeto puede mentir con la verdad, y lo que lo hace proceder de este modo no es otra cosa que la dimensión del Otro, al que resulta necesario engañar para preservarse en tanto sujeto. Por eso la huella que vale para Lacan no es, como en Derrida, simplemente una huella, sino su borramiento: el animal deja huellas, pero sólo el hombre es capaz de borrarlas, o aun más, falsificarlas, para engañar al Otro.

La verdad y su ordenamiento de ficción es uno de los puntos álgidos de la crítica derridiana, minuciosamente desplegado en El concepto de verdad en Lacan. Derrida objeta la idea según la cual toda ficción conllevaría una verdad a desentrañar, la cual comandaría en ella como "el amo de la casa” (Derrida 1977: 25). Por el contrario, señala, los textos se sostienen según su valor y sus leyes intrínsecas, sin que la dupla verdadera/falso deba entrar en juego.

Pero su crítica fundamental al Seminario sobre La carta robada se centra en el tratamiento de la "verdad como desnudez”, metáfora que incluiría también la asimilación de la verdad con la castración y con la mujer. Tanto Lacan como Marie Bonaparte harían la misma lectura del cuento de Poe: ambos leerían en él "la castración de la madre como sentido último y lugar propio de la carta" (Derrida 1977: 77). Es de este modo como Derrida justifi- ca su clásica acusación de fono-logo-falocentrismo respecto del psicoanálisis en la perspectiva lacaniana.

En favor de Derrida hemos de decir que la inspiración heideggeriana en relación con el tema de la verdad es, en los primeros tiempos, bastante evidente en Lacan, pero el último velo, ese que no puede levantarse, no oculta ningún ser sino la falta en ser, sobre él proyectada.

\section{LETRA Y GOCE}

Podríamos decir que a partir de determinado momento en la producción lacaniana la problemática de la verdad deja de ser preeminente, o al menos queda delimitada según otras coordenadas. Al aparecer la cuestión del goce en primer plano, el tema de la verdad se resitúa.

Ya desde el inicio de su obra, Lacan considera que la introducción del sujeto en el lenguaje implica una pérdida del cuerpo en tanto organismo, que sólo se recupera como unidad en la imagen del espejo, siempre y cuando exista el elemento simbólico que permita el reconocimiento del sujeto en esa imagen. Lo simbólico implica la muerte de la cosa, y ese cavado sobre lo real que conlleva la entrada en escena del significante, tiene como correlato la transformación del organismo viviente en un "desierto del goce" (Lacan 2012, 378). El cuerpo ha perdido su goce primordial en el pasaje por las rejillas del lenguaje. Pero esta mortificación del cuerpo por el significante no será total: la pulsión se articulará en los desfiladeros de la demanda del Otro y delimitará zonas que serán reductos de goce, enlazadas a sus respectivos objetos (a). 
En ese marco, la verdad no puede ser otra cosa que aquello que se pone en marcha en el despliegue del saber en la cadena significante. El sujeto, representado por un significante para otro significante, encuentra la verdad al echar a andar su palabra.

Pero el viraje que Lacan produce alrededor de los años setenta en su concepción del inconsciente inducirá, lógicamente, un cambio respecto de la cuestión de la verdad. Definir al inconsciente en tanto estructurado como un lenguaje ya no será suficiente. A lo largo de sus años de trabajo y enseñanza, Lacan se habrá percatado de la existencia de unidades que no se conducen como el significante -esto es, como un elemento negativo cuyo valor solo surge en la cadena por oposición y diferencia respecto de los otros-. Nos referimos a cierta clase de significantes privilegiados que por alguna razón -singular en cada sujeto- tienen un estatuto diferente: valen por sí mismos, no se enlazan a otros, no se disuelven por más proliferación de interpretaciones que promuevan, tocan al cuerpo en un sitio preciso $\mathrm{y}$, en su último vértice, quedan en total disyunción con el sentido. Son, pues, letras.

Lacan también los llama S1 o significantes amos o primarios, pero ¿indica esto una temporalidad? ¿Son cronológicamente anteriores a los demás significantes? Es aquí donde ancora otro punto clave de la controversia con Derrida, que Lacan quiere dejar en claro: nada que ver con la archiescritura, esa "escritura que está desde siempre en el mundo" (Lacan 2009: 82), ironiza, aludiendo a Derrida. Si nos preguntamos acerca de los signos de la percepción -Wahrnehmungszeichen - que Freud ubicara como primeras impresiones recogidas en el aparato psíquico, Lacan nunca dejará de afirmar que son, simplemente, significantes. De modo que el hecho de nombrar las letras como significantes primarios no debe llevarnos a ubicarlas en un momento inaugural del sujeto. La letra no es primaria porque sin pasaje del organismo a través del cuerpo del lenguaje, no hay humanidad posible.

Aquello del orden de la letra aparece cuando algo en esos elementos simbólicos e imaginarios cala más allá del semblante, esto es, de la conjunción de los registros simbólico e imaginario, horadando la carne de lo real: siendo significantes, se rompe su cáscara de sentido y se inscriben en un terreno que no es simbólico, que es gozante, real.

$¿$ Es posible, pues, pensar en una clase de verdad que se atenga a este registro?

\section{VERDAD Y GOCE}

Si la verdad fuera simplemente eso que está escondido y que es menester desvelar -tal como podía deducirse en los inicios de la producción lacaniana- bastaría con "saber bien todo lo que hay que saber" (Lacan 2008, 59) tal como lo afirma Lacan en el Seminario 17. Hay un límite, una impotencia en el saber entendido como despliegue simbólico, puesto que el orden del significante atañe al sentido y no al objeto de goce.

Allí, Lacan recurre al Wittgenstein del Tractatus para reflexionar acerca de la verdad: ella no puede plantearse por fuera de la lógica proposicional, esto es, en términos de proposiciones verdaderas o falsas. Todo lo que puede decirse, si bien concierne a la realidad del sujeto, está ya a nivel del sentido, del semblante: atañe a una realidad construida en el lenguaje. 
Por ello, en última instancia, "no se puede decir nada que no sea tautológico" (Lacan 2008, 63).

Sin embargo, es necesario tener en cuenta lo que Lacan descubre en esos momentos: que todo lo que incumbe al plano de la palabra no se ordena pura y simplemente según el registro simbólico, puesto que del decir también se goza, también resuena el cuerpo en el decir del sujeto, llamado ahora parlêtre, ser hablante, en donde también se escucha lettre, la letra. El significante no es ya solamente ese látigo que regula y mortifica al cuerpo; por el contrario, también lo vivifica, lo hace gozar. Es en ese sentido que la verdad se puede describir como "hermana del goce": no cabe toda en lo simbólico sino que se aloja entre los "residuo(s) del efecto de lenguaje” (Lacan 2008, 71), en ese plus de gozar que se obtiene como resto de los tráficos con la palabra. Afirmaremos entonces, con Miller, que el significante es también lo que "representa el goce para otro significante" (Miller 2000, 161).

La ditmension de la verdad, podríamos decir, no es ya para Lacan solamente lo que posee estructura de ficción sino, más exactamente, lo que se ordena como fixión, recurriendo a este neologismo que utiliza en L'etourdit, en donde resuena la fixierung freudiana -fijación-. La verdad será, pues, conjugación de todo aquello que se despliegue en la palabra del sujeto a nivel de fábula, relato, novela familiar, con los restos que de todo ello resulte fijado, encarnado, inscripto en el registro de lo real.
VERDAD, MENTIRA, ACTO

Derrida ensaya otro abordaje muy diferente del tema de la verdad en una conferencia dictada en Buenos Aires en 1995, titulada Historia de la mentira. Prolegómenos. La cuestión de la verdad es aquí tomada en un ejercicio de lo que él mismo ha denominado "lógica del suplemento", o del "parergon". En ella, algo que aparece como menor, subordinado, derivado de otro elemento principal, termina teniendo la clave de toda la cuestión. La mentira, lejos de complementar a la verdad, la descompleta y muestra que su carácter fragmentario, parcial, refractario a lo unificado, no es accidental sino estructural.

Parergon, plural de parerga, designa tanto los escritos menores de un autor como los elementos del margen en la obra de arte (marcos de cuadros, columnas ornamentales en obras arquitectónicas, etc.). Derrida señala que desde los primeros momentos, la filosofía occidental ha intentado que los parergon no ocupen más que un sitio marginal en el logos y la racionalidad clásica, para no desviar al pensamiento en su búsqueda de los principios, de las cuestiones esenciales. Por ello, realiza el esfuerzo de reintroducir estos elementos considerados secundarios, y al otorgarles el estatuto de objetos a desentrañar, terminan por iluminar el campo de manera insospechada.

En Historia de la mentira, Derrida comienza diciendo que la fábula y el fantasma son dos elementos que, incluso en sentido clásico, no se relacionan con lo verdadero y lo falso, sino que atañen a la virtualidad y el simulacro. A lo largo de su desarrollo visita momentos en la obra de Platón, San Agustín, Kant, Nietzsche, Heidegger, para detenerse en los trabajos 
de Hanna Arendt sobre mentira y política, y en especial en su controvertida noción de "mentira absoluta". Llegado a este punto, su reflexión se adentra en un terreno muy concreto: el lugar de la mentira en la historia, en la política y sus variaciones, y la pertinencia o no de sostener que, en los últimos años, por obra de los cambios producidos en los modos en que los hechos políticos llegan al conocimiento público -con toda la metamorfosis tele-tecno-mediática de por medio, que no alcanzaba, en los años 90, ni a un ápice del grado de desarrollo que, con internet, conocemos hoy- se habría producido una “mutación” en el campo de la mentira.

Por ese notable estilo que le permite, a modo de banda de Moëbius, situar ciertas temáticas cruciales tanto a nivel del sujeto como de lo colectivo -rasgo que considero también presente en el discurso lacaniano- Derrida sitúa históricamente las transformaciones en los modos de la mentira, al tiempo que reflexiona sobre la especificidad del acto de mentir, y lo que señala aquí, por momentos, tampoco difiere demasiado del modo en que lo pensamos en psicoanálisis: "Mentir es querer engañar al otro, y a veces aun diciendo la verdad. Se puede decir lo falso sin mentir, pero también se puede decir la verdad con la intención de engañar, es decir mintiendo. Pero no se miente si se cree en lo que se dice, aun cuando sea falso" (Derrida, 1995).

Derrida va delineando lo que considera decisivo en cuanto a la mentira: ella constituye un acto dirigido a otro -ya San Agustín habría eliminado la posibilidad de que el "autoengaño" sea considerado como tal- y es en las distancias entre lo dicho, el decir y el querer decir, que se dimensiona su verdadero alcance.
Lo que resulta interesante para nuestros propósitos es el modo en que Derrida conjuga el tema de la mentira con la teoría de los actos del habla -speech acts- de Austin. En un texto de los años setenta, Firma, acontecimiento, contexto -que puede leerse en el libro Limited inc.- se explaya sobre lo que cree valioso y lo que juzga objetable en esta teoría. Una de sus críticas recae en la idea de que sólo en las enunciaciones constatativas se haría presente la cuestión de lo verdadero o falso respecto de cierto referente exterior, en tanto las expresiones performativas o realizativas -aquellas que no describen hechos sino que realizan actos por su sólo decir, como en el caso de los juramentos- el tema de la verdad quedaría fuera de juego. En el escrito que estamos comentando, y a contrapelo de esto, Derrida afirma que "cuando los realizativos tienen éxito, producen una verdad cuya fuerza se impone a veces para siempre: la fijación de una frontera, la instauración de un Estado son siempre violencias realizativas que, si las condiciones de la comunidad internacional lo permiten, crean el derecho. (...) Al crear el derecho, esta violencia realizativa -que no es ni legal ni ilegal- crea lo que luego se tendrá por una verdad de derecho, verdad pública dominante y jurídicamente incuestionable" (Derrida, 1995).

Así es como Derrida consigue, por la vía de la mentira, incidir una vez más en una concepción de la verdad que se aleja de la idea de objetividad, adecuación o mero "tema de un enunciado constatativo", y dejar sentado que "la verdad tanto como la realidad no es un objeto dado de antemano que sólo se trataría de reflejar adecuadamente" (Derrida: 1995). 


\section{DIVERGENCIAS Y ENCUENTROS POSIBLES}

A medida que avanza en la construcción de su enseñanza, y fundamentalmente a partir de los 70, la interpretación analítica según Lacan tiene todos los rasgos de lo que podríamos llamar un acto, o, en términos austinianos, una enunciación performativa, puesto que permite hacer existir un decir más allá de lo dicho. La interpretación debería "producir olas" (Lacan, 1975) en lugar de dirigirse a cierta verdad engañosa que habita el sentido con que cada sujeto se explica su mito individual. Una verdad concebida como "hermana del goce" precisa, pues, de un tratamiento que exceda el ámbito de las significaciones.

Sin embargo, antes de llegar a esas unidades depuradas de goce que son los significantes desprendidos de la cadena o letras, un análisis ha de remontar ríos de sinsentido y sentido recompuesto, con sus bifurcaciones y dislocamientos periódicos que inauguran otro arroyo, otra línea de agua antes impensada, para llegar por fin a un lugar donde ya no hay nada de sentido, sino algo que es porque es, digamos, la letra. No es lo mismo el sinsentido de la letra, que podemos llamar "terminal", que el sinsentido que introduce el significante permanentemente por el hecho de que se desplaza y se escande, haciendo aparecer ese otro significante que estaba elidido.

Puesto que hay un punto donde el análisis se topa con lo real, debido a que el tratamiento del goce por la vía de la palabra es limitado, un análisis es, para Lacan, terminable. En determinado momento, el fluir caudaloso de la cadena significante se detiene y se encuentra con ese lugar donde "hay del Uno", un Uno suelto, desencadenado, sea este un S1, una letra, o ambos.
Pero Derrida sostiene exactamente lo contrario: "el análisis es interminable porque no hay elemento indivisible u origen simple”. Para Derrida, podríamos decir, no "hay del Uno", y es por eso que la diseminación es virtualmente infinita. "La divisibilidad, la disociabilidad, y por lo tanto la imposibilidad de detener un análisis" -afirma Derrida- "así como la necesidad de pensar la posibilidad de esta indefinitud, si uno se atuviera a ella, sería quizás la verdad de la deconstrucción.” (Derrida 1998: 55).

El problema radica en el modo en que Derrida piensa el trabajo del análisis. Cuando juzga al psicoanálisis como, digamos, empresa descifradora de obras de arte, así como cuando pondera la práctica analítica, supone que el recorrido se realiza en un viaje hacia los orígenes. Es por ello que se hace necesario sostener que la letra no es originaria.

En Derrida no hay problemática del agotamiento del sentido en el campo de la diseminación, a la cual le supone una voluntad permanente de remitir a nuevos contenidos sin solución de continuidad, pese a no ser ella quien controla el juego. Pero cierta dimensión equivalente al real lacaniano podría alojarse en su idea de acontecimiento, de la irrupción de lo imposible, de apertura al porvenir y a la alteridad radical. Y, fundamentalmente, tanto su tratamiento del concepto de verdad como su noción de justicia - ver su texto Fuerza de ley, en donde pondera positivamente cierta perspectiva nietzscheana en la cual el "valor de la fuerza" da la clave certera de algo que en la tradición metafísica occidental se ha disimulado debajo del empuje a la delimitación entre lo verdadero y lo falso- contemplan el hecho 
performativo y la fuerza del acto en sí, como fundadores de un campo de derecho más allá de lo constatativo, lo cual constituye un punto interesante para pensar en confluencia con los últimos desarrollos en la obra de Lacan. Se trata, pues, de una tarea a realizar.

\section{REFERENCIAS BIBLIOGRÁFICAS}

Derrida, J. (1986) De la gramatología. México, Siglo XXI. (1979) El concepto de verdad en Lacan. Argentina, Homo Sapiens. (1998) Resistencias del psicoanálisis. Barcelona, Paidós. (2010) Fuerza de ley. El fundamento místico de la autoridad. Madrid, Tecnos.

(1988) Limited inc. U.S.A., Northwestern University Press.

(1998) Resistencias del psicoanálisis. Barcelona, Paidós.

Historia de la mentira. Prolegómenos. Conferencia dictada en Buenos Aires en 1995. Organizada por la Facultad de Filosofía y Letras y por la Universidad de Buenos Aires. URL http://flaneurassegut.org/docs/ derrida-textos/Historia_de_la_mentira_DERRIDA.pdf Página web http:// flaneurassegut.org/

Freud, S. (1976) El chiste y su relación con lo inconsciente (1905)- "III-Las tendencias del chiste”, Vol. VIII, Obras completas. Buenos Aires, Amorrortu.

LacAn, J. (2002) Escritos 1. Buenos Aires, Paidós.

XXI.

(1988) Escritos 2. México, Siglo

(2012) Otros escritos. Buenos

Aires, Paidós.

(1981) Seminario 1 Los escritos técnicos de Freud (1953-1954). Buenos Aires, Paidós.

(2010) Seminario 3, Las Psicosis (1955-1956). Buenos Aires, Paidós. (2008) Seminario 17, El reverso del psicoanálisis (1969-1970), Buenos Aires, Paidós.

(2009) Seminario 18, De un discurso que no fuera del semblante (1971). Buenos Aires, Paidós.

(2004) Reseñas de enseñanzas. Buenos Aires, Manantial.

Conferencia en la Universidad de Yale, Kanzer Seminar, 24 de noviembre de 1975. En Conferencias y charlas en Universidades norteamericanas, URL https://www.lacanterafreudiana.com.ar $/ 2.5 .1 .26 \% 20 \% 20 \% 20$ $\% 20$ CONFERENCIAS $\% 20$ Y $\% 20$ CHARLAS \% 20EN\% 20UNIVERSIDADES \%20 NORTEAMERICANAS, \%201975.pdf Página web https://www.lacanterafreudiana.com.ar/

Miller, J.A. (2000) El lenguaje, aparato de goce. Buenos Aires, Colección Diva. 
María Laura Frucella es psicoanalista y escritora. Doctora en Humanidades por la Universidad Pompeu Fabra de Barcelona, Psicóloga (U.N.R) y Especialista en Psicología en Educación (U.N.R).

Ha sido docente e investigadora en la Facultad de Psicología de la U.N.R. desde 1992 hasta 2002, en las cátedras "Epistemología" y "Residencia Educativa de pre-grado".

Miembro del Fòrum Psicoanalític Barcelona. Integrante de la Comisión directiva del Centro de Investigación P\&S -Psicoanálisis y Sociedad-. Miembro del Equipo de Coordinación de Umbral, Red de asistencia "psi".

Dirección: Aragón 178, 5to 4ta, 08011, Barcelona, España

Email: 1frucella@hotmail.com

Teléfono: (34) 637434970 